\title{
Calcification of bioprosthetic heart valves and its assessment
}

Jeffrey M. Gross, PhD

Be not the first by whom the new are tried, Nor yet the last to lay the old aside. -Alexander Pope, An Essay on Criticism

From Medtronic Heart Valves, Santa Ana, Calif.

Received for publication Dec 6, 2000; accepted for publication Dec 12, 2000.

Address for reprints: Jeffrey M. Gross, $\mathrm{PhD}$, Medtronic Heart Valves, 1851 East Deere Ave, Santa Ana, CA 92705 (E-mail: grossj1@medtronic.com).

J Thorac Cardiovasc Surg 2003;125:S6-8

Originally published in J Thorac Cardiovasc Surg 2001;121:428-30.

Copyright () 2003 by The American Association for Thoracic Surgery

$0022-5223 / 2003 \$ 30.00+0$

doi: $10.1067 / \mathrm{mtc} .2003 .208$

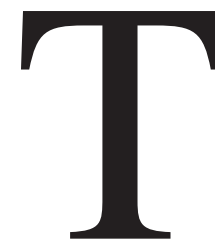

his quotation befits the surgical community as it collectively ponders how much technology to embrace with respect to current and future bioprosthetic heart valve designs. It can be argued that current regulatory guidance document governing development of these prostheses adequately safeguards against the potential for catastrophic structural failures decoupled from biologic influence, for example, stent fracture and tissue dehiscence. The current state of preclinical assessment for the "biologic degradation" of the valvular components is not as predictive given the inherent variability and complexity of the human biologic system into which these devices are implanted. Granted, preclinical evaluation in a variety of animal models is used to access a valve design's functionality and resistance to calcification; however, it is often difficult to extrapolate such data to the long-term human experience.

The intent of this editorial is to provide a broad overview of what is thought to be the mechanisms of calcification in bioprosthetic heart valves, list the current fixation processes in the literature, and examine how prostheses are evaluated for their antimineralization efficacy. Above all, it is my hope that this editorial will spur thought and challenge industrial, clinical, and academic scientists to seek better techniques for the evaluation of new tissue fixation processes.

Glutaraldehyde-fixed heart valves were first implanted in 1967 after it was determined that glutaraldehyde stabilized collagenous biomaterials. ${ }^{1,2}$ Although valves thus treated were nonthrombogenic, they failed because of calcific degeneration. ${ }^{3,4}$ Much has been written yet little has been proven as to the mechanisms for this calcification. It has been postulated that calcium phosphate crystals containing sodium, magnesium, and carbonate nucleate due to devitalization of the cells and thus inactivation of the calcium pump. ${ }^{5}$ It has been demonstrated that calcification does initiate in the cells ${ }^{6}$; however, this would appear to be at odds with the fact that cusps stored in glutaraldehyde for more than 1 year no longer calcify, ${ }^{7}$ and valves treated with high concentrations of glutaraldehyde have diminished calcification. ${ }^{8}$ In both cases, cells and their remnants are present in the collagen/elastin matrix. For this reason, work has also focused on decellularization of the porcine collagen/ elastin matrix. ${ }^{9}$ Membrane-bound phospholipids have also been associated with calcification nucleation due to alkaline phosphatase hydrolysis. ${ }^{10}$ Ethanol has been used to remove phospholipids and mitigate calcification, yet phospholipids have also been removed with chloroform-methanol yielding less than optimum antimineralization efficacy on the basis of rat subcutaneous experiments. ${ }^{11}$ This would indicate that phospholipid removal alone is not sufficient to mitigate calcification. Lipid extraction can also be performed through tissue processing with detergent compounds such as sodium dodecyl sulfate. Subcutaneous rat studies indicate this approach to be efficacious, although circulatory models have demonstrated mixed results. ${ }^{12}$ The primary concern with lipid extraction methods is the potential for collagen matrix degradation if the processes are too aggressive. ${ }^{10}$ Free aldehyde within the tissue matrix has been thought to be an initiator for calcification as well. 
This is supported by studies that demonstrate that aldehydebinding agents such as alpha-amino oleic acid (AOA; Biomedical Design, Marietta, Ga), L-glutamic acid, and aminodiphosphonate prevent cusp calcification. ${ }^{13-16}$ Yet, post treatment with the amino acid lysine does not prevent cuspal calcification. ${ }^{17}$ The foregoing often conflicting information serves to underscore the complexity of the bioprosthetic valve calcification process and emphasizes the multiplicity of pathways by which calcification can initiate.

Because theories for bioprosthetic valve calcification exist without definitive proof, the approaches used by industry and researchers to seek solutions to this clinical failure modality have been based on observed phenomena. Processes have been developed and then assessed to ensure reproducibility, desired tissue biomechanics, desired surface chemistry, matrix stability, and resistance to calcification through a battery of in vitro and in vivo tests. A variety of treatments have been used clinically as well as experimentally. They may be broken down into two broad categories: modifications to glutaraldehyde processed tissue and nonglutaraldehyde processes. The modifications to glutaraldehyde processed tissue include but are not limited to treatments with detergents such as sodium dodecyl sulfate and Tween-80 to remove phospholipids, ${ }^{12}$ ethanol preincubation to remove phospholipids, ${ }^{11}$ covalently bound AOA, L-glutamic acid and aminodiphosphonate to bind free aldehydes, ${ }^{13-17}$ and detoxification processes using urazole ${ }^{18}$ and homocysteic acid. ${ }^{19}$ Nonglutaraldehyde processes include but are not limited to epoxy compounds, ${ }^{20}$ dye-mediated photo-oxidative reactions including PhotoFix ${ }^{21}$ (Sulzer Carbomedics, Austin, Tex) and carbodiimide compounds including Ultifix (Biomedical Design).22

Some of these processes have clinical experience and some do not. Clinical data are difficult to access relative to bioprosthetic valvular calcification, because valves are not usually explanted unless demonstrable valvular performance issues are present that cause stenosis and/or incompetence. This is further confounded by the fact that one must also layer into the analysis the host of patient factors that can bias interpretations. The resulting analysis in general yields a statement as to whether a valve was calcified or not. Although this is valuable, it does not provide insight as to the mechanism for the presence of or lack of calcification. This may change, however. A recent publication by Melina and associates ${ }^{23}$ demonstrated a real time in vivo technique using electron beam computed tomography to assess calcification in both aortic leaflets and aortic wall with stentless xenografts and homografts. This represents a first hope at getting the mechanistic question answered noninvasively in human beings.

The root cause for our inability to determine the mechanisms for bioprosthetic heart valve calcification lies in the limitations of the models we use in the pursuit of this knowledge. Current preclinical in vivo techniques for the assessment of bioprosthetic heart valve calcification revolve around analysis of explants from two animal models - the rat subcutaneous model and the juvenile sheep. Values for calcification from the rat subcutaneous model favorably trend with those from the juvenile sheep. ${ }^{10,11}$ Thus, despite being static and lacking blood contact, the rat subcutaneous model can be used to screen processes before committing to the expense of large animal studies. In addition to the standard 8-week implant duration reported by most investigators using the subcutaneous rat model, spatial studies should be undertaken with freshly processed and aged shelf life valves to ensure any effect noted is in fact present as opposed to simply offset in time. ${ }^{24}$ The sheep model uses an orthotopic implant. As such, it is blood contacting and integrates the unknown role of cyclic mechanical stress into the determination of calcification resistance. The downfall is that, because of the time and expense associated with conducting such studies, the use of statistically valid sample sizes is prohibitive, rendering results difficult to interpret should biologic variation occur. In general, the predictive capacity of both models suffers from differences between their lipoprotein profile and accelerated calcium metabolism as compared with human beings. Neither incorporates the cardiovascular disease effects and neither accurately reflects the coagulation pathways of human beings. The latter is important, as at present there is no validated thromboembolism model for the assessment of modified and/or new tissue fixation/stabilization technology incorporated into heart valve designs.

Given the limitations of preclinical in vivo bioprosthetic valvular calcification assessment techniques, researchers have long sought to develop in vitro methods. Calcium-rich solutions have been applied to bioprosthetic valves placed into dynamic operation in vitro at a variety of frequencies. ${ }^{25-27}$ The limitation of this technique revolves not around the ability to produce calcification but to correlate the histologic and ultrastructural manifestation of this calcification to that seen in the animal models and in human beings. In this issue of the Journal [J Thorac Cardiovasc Surg 2001;121:500-9], Pettenazzo and associates describe their in vitro test system and results. They were able to produce extrinsic nodular and laminar calcific deposits. The intrinsic calcification noted on the basis of transmission electron microscopic analysis was associated at the microstructural level with collagen and elastin fibrils. Most notably, however, they saw minimal calcification associated with xenograft cells and cellular debris. This is at odds with evidence reported from biologic models and human explants. ${ }^{5,6}$ This is not to say that such modeling is not valuable. Rather, it underscores the need for additional validations with this technology. Greater sample size is necessary to ensure the model's sensitivity. Spatial studies 
must be completed to determine apatite initiation sites and their growth characteristics, and processes with data from animal models should be assessed in the present in vitro model to determine whether a correlation exists.

The ultimate answer is that no single model or analysis will contain the necessary predictive power to determine a bioprosthetic heart valve's potential to calcify. The key to the assessment of bioprosthetic valvular calcification lies in the usage of multiple models and the understanding of their limitations. As we collectively move the state of the art forward for the assessment of calcification efficacy with bioprostheses, the patients receiving these devices will ultimately benefit because new technology will have lower risk with greater hope of demonstrating clinical efficacy. Once achieved and borne out by the scrutiny of science, we can then say, on this one issue, that Alexander Pope's first comment should not apply.

\section{References}

1. Nimni ME. A defect in the intramolecular and intermolecular crosslinking of collagen caused by penicillamine. I. Metabolic and functional abnormalities in soft tissues. J Biol Chem. 1968;243:1457-66.

2. Strawich E, Hancock WD, Nimni ME. Chemical composition and biophysical properties of porcine cardiovascular tissues. Biomat Med Dev Artif Organs. 1975;3:309-18.

3. Schoen FJ, Levy RJ. Bioprosthetic heart valve failure: pathology and pathogenesis. Cardiol Clin. 1984;2:717-39.

4. Milano A, Bortolotti U, Talenti E, Valfre C, Arbustini E, Valente M, et al. Calcific degeneration as the main cause of porcine bioprosthetic valve dysfunction. Am J Cardiol. 1984;53:1066-70.

5. Schoen FJ, Levy RJ, Piehler HR. Pathological considerations in replacement heart valves. Cardiovasc Pathol. 1992;4:69-73.

6. Schoen FJ, Levy RJ, Nelson AC, Bernard WF, Nashef A, Hawley M. Onset and progression of experimental bioprosthetic heart valve calcification. Lab Invest. 1985;52:523-32.

7. Schryer PJ, Tomasek ER, Starr A, Wright JT. Anticalcification effect of glutaraldehyde preserved valve tissue stored for increasing time in glutaraldehyde: In: Bodnar A, Yacoub M, editors. Proceedings of the Third International Symposium on Biologic and Bioprosthetic Valves. New York: Yorke Medical Books; 1986, p. 471-2.

8. Zilla P, Weissenstein C, Bracher M, Zhang Y, Koen W, Human P, et al. High glutaraldehyde concentrations reduce rather than increase the calcification of aortic wall tissue. J Heart Valve Dis. 1997;6:502-9.

9. O’Brien MF, Goldstein S, Walsh S, Black KS, Elkins R, Clarke D. The SynerGraft valve: a new acellular (nonglutaraldehyde-fixed) tissue heart valve for autologous recellularization: first experimental studies before clinical implantation. Semin Thorac Cardiovasc Surg. 1999;11(Suppl 1):194-200.

10. Schoen FJ, Harasaki H, Kim K, Anderson HC, Levy RJ. Biomaterial associated calcification: pathology, mechanisms, and strategies for prevention. J Biomed Mater Res. 1988;22:11-36.
11. Vyavahare N, Hirsch D, Lerner E, Baskin J, Schoen FJ, Bianco R, et al. Prevention of bioprosthetic heart valve calcification by ethanol preincubation: efficacy and mechanisms. Circulation. 1997;95:47988.

12. Schoen FJ, Levy RJ. Heart valve bioprostheses: antimineralization. Eur J Cardiothorac Surg. 1992;6(suppl 1):S91-4.

13. Gott JP, Chih P, Dorsey L, Jay JL, Jett GK, Schoen FJ, et al. Calcification of porcine valves: a successful new method of antimineralization. Ann Thorac Surg. 1992;53:207-16.

14. Jones M, Eidbo EE, Hilbert SL, Ferrans VJ, Clark RE. Anticalcification treatments of bioprosthetic heart valves: in vivo studies in sheep. J Cardiovasc Surg. 1989;4:69-73.

15. Grabenwöger M, Sider J, Fitzal F, Zelenka C, Windberger U, Grimm $\mathrm{M}$, et al. Impact of glutaraldehyde on calcification of pericardial bioprosthetic heart valve material. Ann Thorac Surg. 1996;62:772-7.

16. Webb CL, Benedict JJ, Schoen FJ, Linden JA, Levy RJ. Inhibition of bioprosthetic valve calcification with aminodiphosphonate covalently bound to residual aldehyde groups. Ann Thorac Surg. 1988;46:309-16.

17. Chen W, Kim JD, Schoen FJ, Levy RJ. Effect of 2-amino oleic acid exposure conditions on the inhibition of calcification of glutaraldehyde crosslinked porcine aortic valves. J Biomed Mater Res. 1994; 28:1485-95.

18. Weissenstein C, Human P, Bezuidenhout D, Zilla P. Glutaraldehyde detoxification in addition to enhanced amine cross-linking dramatically reduces bioprosthetic tissue calcification in the rat model. J Heart Valve Dis. 2000;9:230-40.

19. Valente M, Pettenazzo E, Gaetano T, Molin GM, Martignago F, DeGiorgi $G$, et al. Detoxified glutaraldehyde cross-linked pericardium: tissue preservation and mineralization mitigation in a subcutaneous rat model. J Heart Valve Dis. 1998;7:283-91.

20. Okoshi T, Noishiki Y, Tomizawa Y, Morishima M, Terada R, Koyanagi $\mathrm{H}$. Long-term results of a new antithrombogenic cardiac wall substitute. ASAIO Trans. 1989;35:391-5.

21. Moore MA. Stabilization of pericardial tissue by dye mediated photooxidation. J Biomed Res. 1994;611-8.

22. Girardot JM, Girardot MN. Amide cross-linking: an alternative to glutaraldehyde fixation. J Heart Valve Dis. 1996;5:518-25.

23. Melina G, Rubens MB, Birks EJ, Bizzarri F, Khaghani A, Yacoub MH. A quantitative study of calcium deposition in the aortic wall following Medtronic Freestyle compared with homograft aortic root replacement: a prospective randomized trial. J Heart Valve Dis. 2000; 9:97-103.

24. Girardot MN, Girardot JM, Torrianni M. Alpha-aminooleic acid (AOA) anticalcification effect on glutaraldehyde-fixed heart valves: shelf-life studies: In: Gabbay S, Frater RM, editors. New horizons and the future of heart valve bioprostheses. 1st ed. Austin: Silent Partners, Inc; 1994. p. 41.

25. Fisher AC, Bernacca GM, Mackay TG, Dimitri WR, Wilkinson R, Wheatley DJ. Calcification modeling in artificial heart valves. Int $J$ Artif Organs. 1992;15:284-8.

26. Kapolos J, Mavrilas D, Missirlis Y, Koutsoukos PG. Model experimental system for investigation of heart valve calcification in vitro. J Biomed Mater Res. 1997;38:183-90.

27. Glasmacher B, Deiwick M, Reul H, Knesch H, Keus D, Rau G. A new in vitro test method for calcification of bioprosthetic heart valves. Int J Artif Organs. 1997;20:267-71. 